\title{
Management Innovation in Brazilian Technology Companies: The Challenges Faced by Managers in the Practice of Innovation
}

\author{
Luan Carlos Santos Silva*, João Luiz Kovaleski, Silvia Gaia, Pedro Paulo de Andrade Júnior \\ Department of Production Engineering and Technology Transfer Research Group, Federal University of Technology—Paraná, Utfpr, \\ Brazil. \\ Email: *luancarlosmkt@gmail.com, kovaleski@utfpr.edu.br, gaia@utfpr.edu.br, pedropaulo@utfpr.edu.br
}

Received August $10^{\text {th }}, 2012$; revised September $7^{\text {th }}$, 2012; accepted October $7^{\text {th }}$, 2012

\begin{abstract}
The overall objective of the study was to analyze the process of innovation management in technology companies in an Informatics Nucleus in the State of Bahia, Brazil. The research was qualitative and by the point of view of its nature was applied. It was also characterized as a descriptive research. In order to face challenges in the market, managers of companies from Informatics Nucleus must continually innovate in their processes by acquiring new organizational knowledge and showing an entrepreneurial and innovative approach within the market, the execution and maintenance. Expansion of such actions has become fundamental to the further strengthening of technology companies in the State of Bahia.
\end{abstract}

Keywords: Innovation Management; Technology Companies; Octagon Innovation

\section{Introduction}

This paper was developed in the Research Group on Management of Technology Transfer, more specifically: Agents of Innovation as a facilitator of the Technology Transfer. This group is part of the Post Graduate Program in Production Engineering from the Federal Technological University of Parana, and brings to discussion, reflections on the understanding of innovation management in informatics companies in many approaches which do not take into consideration the specific regionand market where they operate, as well as the direct rela tionship in the process of innovation.

The overall objective of the study was to analyze the process of innovation management in companies of Information and Communication Technology (ICT) of the Informatics Nucleus of Ilhéus in Bahia State.

According to SINEC (Syndicate of Industries of Electrical Devices, Electronics, Computers, Information and Related Items from Ilhéus and Itabuna), the electro-electronics industry has currently been highlighted in Brazil. As an example, the Informatics Nucleus from Ilhéus was responsible, in 2008 , for $20 \%$ of produced and sold desktops in the country. This number was reduced to $15 \%$ in 2010, due to a series of problems faced by the companies in the Nucleus [1].

*Corresponding author.
The SINEC has represented companies in the region since November 1998. It emerged with the aim to represent and fight for the interests of entrepreneurs who believe in the economic potential of this sector. Throughout these years, it has been seeking to develop new proposals for the Nucleus, as the improvement of physical infrastructure and the increasing of skilled labor, which contributes to the companies to be able to absorb the work of professionals in the region.

The Pole region also has the infrastructure from the University of Santa Cruz State (UESC), which can be planning and developing advanced technologies and advising on the proper protection of intellectual property generated by the Center for Technological Innovation UESC.

UESC has been busy on interaction with the productive environment, in order to strengthen the research capacity of the institution and technologic companies' content. It started in 2006, through a program which main objective was to get closer to companies in the Informatics Nucleus from Ilhéus. Such program resulted in the development of a series of applied research projects and technological extension, with the raising of funds from the Informatics Law, in order of one million dollars from 2007 to 2010, with emphasis on the creation of the Laboratory of Polymers (LAPOS) and the Laboratory of 
Mechanical Testing and Strength of Materials (LER-NER).

Partnerships in the area of Information and Communication Technology (ICT) has generated a proposal to establish the Technology Park in the South of Bahia, involving a major coordination among public government (state and local), academy and companies in the Nucleus. This project is still in preparation.

\section{Literature Review}

\subsection{Innovation}

In the literature, "innovation" can refer to a result of an innovative process or to the innovative process itself [2]. However, to some authors the specific term "innovation" is only used for the result of the innovation process, and "innovation management", for the management of activities that attempt to control the innovation process [3].

Innovations are often classified in terms of the achieved technological level, which produces categories [4].

The term innovation, in particular, means news [5]. The innovative activity may be related to new products, new services, new methods of production, opening of new markets, new sources of supply, and new forms of organization.

Innovation has been characterized as a process of marketing for a new product developed in practice $[6,7]$. Johne [8] distinguishes three types of innovation: product innovation, process innovation and market innovation. Product innovation provides the most obvious way to generate revenue. Process innovation provides the means for safeguarding and improving the quality saving costs. Market innovation aims to improve the mix of target markets inside the selected markets. Its purpose is to identify new or improved markets and new potential or better ways to serve the target markets.

The role of the effective use of market information is emphasized particularly in the case of product and market innovation, including the generation, internal diffusion, and market information of companies [9-11].

Innovation is characterized by its uniqueness, and it can be highly radical, radical, intermediate, incremental innovation, or lower [12].

Highly radical innovation is a unique product, original or a system that will turn the existing ones into obsolete ones. It is based on proprietary technology beyond the art. Radical innovation is a new product or system with the original state of the art, proprietary technology will significantly expand the capacity of existing ones. Innovation is an intermediate product with new technology itself; however it can be duplicated by others. It is a mixture of standard and special features. Incremental innovation refers to a significant expansion of the product char- acteristics unique to the original adaptation. Minor innovation relates to incremental improvement related to existing products. It is a standardized product and an application of the current technology. It does not generate patent or require research and development.

Innovation is also characterized by the question: for whom is it new? [5]. This refers to the adaptation unit, which can be examined in terms of novelty for the company, to the market and to the industry $[5,13,14]$.

\subsection{Innovation Management}

The term innovation management involves the managing of entire innovation process from initial idea generation through product or process development/adaptation of bringing to market or start. This includes both strategic and operational issues [7,15]. At the gross level, according to Ojasalo [16], a new product development process can be divided into three phases: Idea generation, technical development and marketing.

The process of innovation refers to multifunctional activities that create innovations through the departments of the company. Strategic planning means planning for technology projects, technology or expertise in order to maintain a balanced portfolio of technologies or skills. Organizational change is relevant in the context of innovation, since it is often difficult to talk about innovation without considering organizational change. Business development is also relevant in the context of innovation because innovation can either drive or be driven by the development company.

A study based on innovative companies led researchers Scherer and Carlomagno [17] to create a tool called the innovation Octagon, able to make a diagnosis of innovative potential, as management in innovative enterprises.

The tool is structured in eight dimensions, including the main points to be managed to enhance innovative productivity, beginning from the strategy to process of transforming ideas into results [17].

The eight dimensions proposed by the authors refer to the following aspects:

- Innovation strategy: How does the company articulate the direction of innovation initiatives?

- Leadership for Innovation: How is the understanding of leadership and the necessity and relevance of innovation? How do managers support the atmosphere of innovation?

- Culture of Innovation: What does the top management say and do in order to create an atmosphere which provides innovation?

- Relationships for Innovation: How does the company use partners, customers and competitors in the crea- 
tion and refinement of ideas?

- Structure for Innovation: Where is the innovation activity located and how is it organized?

- People of Innovation: How is the support for innovation, its incentives and recognition?

- Process of Innovation: How are innovation opportunities created, developed and evaluated?

- Funding for Innovation: How are innovation initiatives financed?

The following guidelines are also relevant for managers to structure their firms to innovate. First, the company must have strong support of innovation as a way of life, by its example, words and actions. Secondly, the company must remain close to their customers, partly in response to their expressed needs, but mainly to figure out what they want in the future, preferably before customers get to know them. Thirdly, there must be an internal procedure to keep all the innovation projects under reconsideration-continuous, so that the work is done simultaneously on all fronts, but it remains cohesive and compatible [18].

Fourth, an innovative culture usually involves a considerable freedom of action, substantial resources for education at all levels in the company on new technologies and the use of small teams of employees who have many skills. Fifthly, to sustain an innovative culture, it is important that employees who successfully innovate should be noticed and rewarded.

Market orientation has a significant positive influence on the success of new products and, consequently, and it is a crucial element of innovation management [19-21].

\section{Methodology}

The research was qualitative and the point of view by its nature is applied. It was also characterized as a descriptive research. At first, the research consisted of an analysis of secondary sources such as bibliographic references and researches from other sources. In the second stage, the references analyzed in the theoretical framework served as support for gathering information directly with the object of study.

The research population consists of Information Technology Companies (ICT) of the Informatics Nucleus from Ilhéus (Bahia). According to information by SUDIC, Superintendent of Industrial and Commercial Development of the Bahia State [21,22], currently the Nucleus has 49 companies. For the purpose of this study, 25 companies were selected for the questionnaire, but only 13 of them responded to the research (up to 27\%).

The sample selection was random. The questionnaire was applied from March to April 2012. The first contact was made by telephone with the managers. After that, the questionnaire was sent to them by e-mail.
This sample constituted by 13 companies was able to give a general view on innovation management as the researched Nucleus, according to SINEC, is responsible for the production of $20 \%$ of the total commercialized computers in Brazil [1].

People with strategic positions in informatics companies were selected for the questionnaire. In each company the tool was applied with two managers, one manager of the production area and another from the company's planning, totalizing 26 surveyed managers.

The research instrument was a questionnaire with 24 questions [17]. The applied questionnaire consists of the Octagon model of Innovation Management or Innovation Assessment, addressing eight points in the process, such as: Leadership, Strategy, Relationships, Culture, People, Structure, Process and Funding.

The tool was analyzed using Likert scale, with a score from 1 to 7 where 1 refers to a strongly disagree opinion while 7 means that the person strongly agrees. The higher the score applied, the better the management of innovation in the enterprise.

\section{Results and Data Analysis}

A research with the managers allowed observing with greater efficiency and effectiveness the operation of the environments regarding innovation management.

It is worth noting before the analysis that each point analyzed in the octagon of innovation management had three questions directed to its context, in a total of 24 questions.

The following figure (Figure 1) presents the consolidated results about the eight points of the octagon of innovation in the 13 companies.

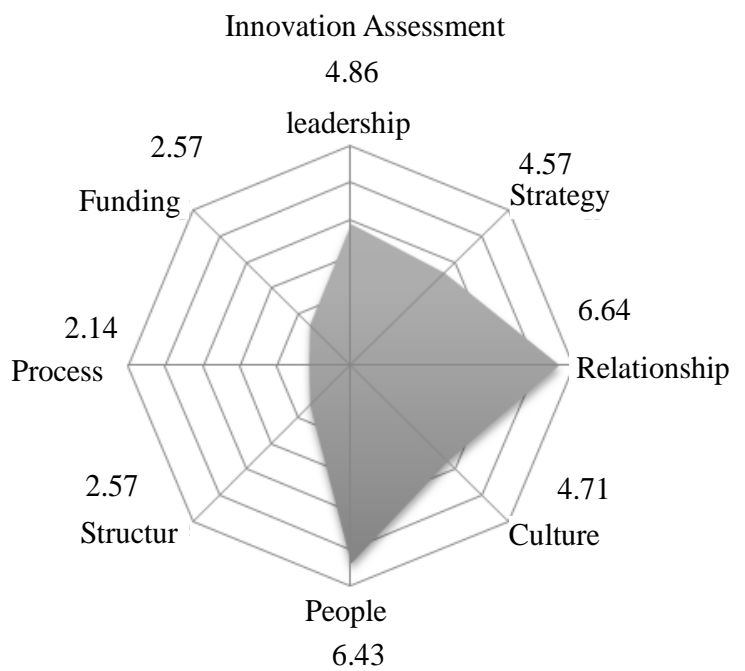

Figure 1. Results of the octagon innovation in companies from informatics nucleus. 
The most critical points in the Informatics Nucleus, regarding innovation management, were: Process with 2.14 points, followed by Structure and Funding with 2.57 points.

Taking into consideration the processes, companies found barriers to use project management tools to drive as well as to systematically evaluate the results of innovation initiatives, making it hard to provide a framework for generating and selecting ideas deficit.

In structure, they found difficulties to breakthrough highly innovative initiatives. They do not have a flexible organizational structure, with many hierarchical levels and little decentralization of decisions so initiatives and innovation activities does not have a defined coordination in companies.

With regard to the Funding, most companies do not have a specific budget for innovation projects. New ideas are not evaluated according to performance measures which take into account the risks and uncertainties, and have difficulties to seek financial resources for innovation in different sources, because they don't have a capable team for such activity.

In addition, points related to the human factor had the best scores, including: Relationships with 6.64 points and people with 6.63 points.

For such matter, the Nucleus companies use their customer's networks, suppliers and even competitors to generate and refine new ideas. They get to know the revealed and unrevealed needs of customers and non-customers. They have a process for tracking new markets, trends and technology. The need for innovation is understood by all within the companies, as well. The knowledge and tools they need to innovate are known by everyone within the organization and the team has a high diversity of knowledge, values, and career interests.

The points Leadership, Strategy and Culture had been scored between 4.5 to 5.0 , which are considered good scores in the process of innovation management.

Considering Leadership, companies have clarity about the concept and importance of innovation. The performance of leaders is evaluated with specific metrics related to their performance in the process of managing innovation, dedicating time and attention to the monitoring of technological innovation projects.

For the Culture factor, managers provide time, benefits and incentives (financial and nonfinancial) for innovation. In general, companies allow employees to take risks and make mistakes in the search for new solutions, and use communication mechanisms to foster innovation in the enterprise.

Regarding to the Strategies, innovation initiatives are aligned with the strategy of each company. They seek to present a clear focus on growth through innovation and themes development, objectives and targets set for innovation.

Data show that the companies in the Informatics Nucleus of Ilhéus have a team of highly skilled managers and employees with knowledge about their technologies and innovations, but when it comes to the practice related to innovation, they have a deficient structure, as reported in the research, process with 2.14 points, Funding and Structure with 2.57, which are essential to the practice of innovation in enterprises.

\section{Conclusions}

Informatics companies are not alien to oscillations that are occurring in the current competitive scenario. However, managers have not given proper treatment for issues related to specificities of the company and individuals to promote innovation.

It seems to be necessary that they create an appropriated environment to organizational learning: flexible and without rigid hierarchical structures. Knowledge of technologies and innovations is not only essential to this process, but essential. Practice linked to knowledge is probably the best bet for even greater success. Research has shown that the practice of the processes related to innovation is the factor preventing companies from increasing their capacity of innovation.

Universities and Research Centers may be an excellent alternative for companies in the diffusion of innovation to ensure the protection of knowledge generated and technology transference.

The Information Technology Act allowed greater structuring of the Nucleus, as well as tax incentives provided by law.

In order to achieve innovation in a consolidated way, using the innovation octagon, managers should promote a network which would include every employee and value creativity and ideas. The following five suggestions aim to be a guideline to improve innovation:

- Turn reactive innovation into proactive one.

Instead of waiting for ideas, companies should provide employees with specific themes to be developed. Themes should reflect the most urgent, up-to-date and relevant issues, such as: Waste reduction, delays, complains, quality and productivity improvement. Such procedure may result in little ideas, but they will be much more useful and important to the company's results.

- Direct creativity in order to achieve innovation.

Focusing on challenges and most relevant opportunities will provide a better way of establishing target issues. Highlighting such issues, directly connect to employees activities, will allow managers and workers to spend time trying to take actions. Once more, such approach will result in little ideas, but they will be ideas 
which are related to the company's needs and priorities.

- Motivate employees to innovate.

Let employees know which are the main challenges that the company is facing and let them propose changes in order to keep the company highly competitive and profitable. Managers can explain the reasons for a chosen theme and then expect for innovative ideas related to such themes.

- Get employees prepared for innovation.

As any competence or ability, creativity can and should be improved. Good will and enthusiasm are not enough to overcome cultural barriers, old habits, and deficiencies. Set a team and provide basic tools for innovation and creative solution of problems. Select and train facilitators who also support the teams in the use of the octagon innovation.

In short, companies should direct their team creativity to well-defined challenges applying tools to overcome barriers and to lead to innovation and new paths.

Companies have been searched for good strategic actions to generate innovation, but they still have a deficient structure. They do not have an effective knowledge management, making it impossible, in many instances, to take actions which would be best taken in companies that work with its members and departments involved in the organization.

However, there is not a unique model for innovation management for all organizations, since each organization has its own characteristics and a culture difference. In order to face such challenges, companies in the Informatics Nucleus must innovate their processes continually, always acquiring new knowledge organization to have an entrepreneurial and innovative approach focused on the market. Implementation, maintenance and expansion of these actions become central to the further strengthening of such companies in the state of Bahia.

\section{REFERENCES}

[1] Sinec, "Industry Union Electrical Appliance, Electronics, Computers, Computer and Related Ilheus and Itabuna," 2012. http://www.sinec.org.br/osinec.php

[2] P. F. Drucker, "Innovation and Entrepreneurship,” Harper \& Row, London, 1985.

[3] A. Drejer, "Situations for Innovation Management: Towards a Contingency Model," European Journal of Innovation Management, Vol. 5, No. 1, 2002, pp. 4-17. doi:10.1108/14601060210415135

[4] C. M. Christensen, "Exploring the limits of the Technology S-Curve, Part 1: Component Technology,” Production and Operational Management, Vol. 1, No. 4, 1992, pp. 334-357. doi:10.1111/j.1937-5956.1992.tb00001.x

[5] J. A. Johannessen, B. Olsen and G. T. Lumpkin, "Innovation as Newness: What Is New, How New and New to
Whom?” European Journal of Innovation Management, Vol. 4, No. 1, 2001, pp. 20-31. doi:10.1108/14601060110365547

[6] C. Freeman, "The Economics of Industrial Innovation," Frances Pinter, London, 1982.

[7] K. E. Dickson and A. Hadjimanolis, "Innovation and Networking amongst Small Manufacturing Firms in Cyprus," International Journal of Entrepreneurial Behavior \& Research, Vol. 4, No. 1, 1998, pp. 5-17. doi:10.1108/13552559810203939

[8] A. Johne, "Successful Market Innovation," European Journal of Innovation Management, Vol. 2, No. 1, 1999, pp. 6-11. doi:10.1108/14601069910248838

[9] J. Ojasalo, "Using Market Information in Generating and Selecting Ideas in New Product Development: Results from an Empirical Study on Innovations Management in the Software Business,” The Business Review, Vol. 1, No. 1, 2003, pp. 71-76.

[10] J. Ojasalo and R. Olkkonen, "Brand Building in Software Product Development: An Empirical Study,” In: N. Pujawan and I. Vanany, Eds., Proceedings of the International Conference on Operations and Supply Chain Management, Bali, 1-7 December 2005, pp. 15-17.

[11] W. G. Biemans and H. Harmsen, "Overcoming the Barriers to Market-Oriented Product Development,” Journal of Marketing Practice: Applied Marketing Science, Vol. 1 No. 2, 1995, pp. 7-25. doi:10.1108/EUM0000000003882

[12] P. A. Abetti, "Critical Success Factors for Radical Technological Innovation: A Five Case Study,” Creativity and Innovation Management, Vol. 9 No. 4, 2000, pp. 208221. doi:10.1111/1467-8691.00194

[13] R. G. Cooper, "Winning at New Products: Accelerating the Process from Idea to Launch,” 2nd Edition, AddisonWesley, Reading, 1993.

[14] M. Kotabe and K. S. Swan, "The Role of Strategic Alliances in High Technology New Product Development," Strategic Management Journal, Vol. 16 No. 8, 1995, pp. 621-636. doi:10.1002/smj.4250160804

[15] R. Rothwell, "Successful Industrial Innovation: Critical Factors for the 1990s,” $R$ \& D Management, Vol. 22, No. 3, 1992, pp. 221-239. doi:10.1111/j.1467-9310.1992.tb00812.x

[16] J. Ojasalo, "Obstacles to Being an Entrepreneur in Finland. Results of an Empirical Study,” In: C. F. Gaulden Ed., Proceedings of the Annual Conference of ASBE Association for Small Business \& Entrepreneurship, Houston, 5-8 March 2003, pp. 23-33.

[17] F. O. Scherer and M. S. Carlomagno, "Innovation Management Practice: How to Apply Concepts and Tools to Leverage Innovation,” Atlas, São Paulo, 2009.

[18] A. M. Mccosh, A. U. Smart, P. Barrar and A. D. Lloyd, "Proven Methods for Innovation Management: An Executive Wish List," Creativity and Innovation Management, Vol. 7, No. 4, 1998, pp. 175-192. doi:10.1111/1467-8691.00108

[19] K. Atuahane-Gima, “An Exploratory Analysis of the Impact of Market Orientation on New Product Perform- 
ance: A Contingency Approach,” Journal of Product Innovation Management, Vol. 12, No. 4, 1995, pp. 275-293. doi:10.1016/0737-6782(95)00027-Q

[20] F. Tomala and O. Senechal, "Innovation Management: A Synthesis of Academic and industrial Points of View," International Journal of Project Management, Vol. 22, No. 4, 2004, pp. 281-287. doi:10.1016/j.ijproman.2003.06.003

[21] L. C. S. Silva, J. L. Kovaleski, S. Gaia, E. A. S. A. Matos and A. C. Francisco, "The Challenges Faced by Brazil's Public Universities as a Result of Knowledge Transfer Barriers in Building the Technological Innovation Center," African Journal of Business Management, Vol. 6, No. 41, 2012, pp. 10547-10557.

[22] Sudic, "Superintendent of Industrial and Commercial Development of the Bahia State," 2012.

http://www.sudic.ba.gov.br/index.htm 